\section{$\underset{\substack{\text { hommes } \\ \text { \& migrations }}}{ }$}

\section{Hommes \& migrations}

Revue française de référence sur les dynamiques

migratoires

1319 | 2017

Réfugiés et migrants au Liban

\title{
Le camp de la Linière détruit
}

Les exilés éloignés du littoral

\section{Chloé Tisserand}

\section{(2) OpenEdition \\ 12 Journals}

\section{Édition électronique}

URL : https://journals.openedition.org/hommesmigrations/3990

DOI : 10.4000/hommesmigrations.3990

ISSN : 2262-3353

\section{Éditeur}

Musée national de l'histoire de l'immigration

\section{Édition imprimée}

Date de publication : 1 octobre 2017

Pagination : 138-140

ISBN : 978-2-919040-39-1

ISSN : $1142-852 X$

\section{Référence électronique}

Chloé Tisserand, «Le camp de la Linière détruit », Hommes \& migrations [En ligne], 1319 | 2017, mis en ligne le 01 octobre 2017, consulté le 28 juin 2022. URL : http://journals.openedition.org/

hommesmigrations/3990; DOI : https://doi.org/10.4000/hommesmigrations.3990 


\section{LE CAMP DE LA LINIÈRE DÉTRUIT : LES EXILÉS ÉLOIGNÉS DU LITTORAL}

Par CHLOÉ TISSERAND, journaliste à La Voix du Nord de Calais et doctorante en sociologie en deuxième année avec le laboratoire CeRIES de l'université de Lille-3.

U n an après notre passage dans le camp de La Linière, le bras de fer entre la municipalité de Grande-Synthe et l'État semble tourner à l'avantage de celui-ci. Dans la nuit du 10 avril, un incendie qui aurait été provoqué suite à une bagarre au couteau (six blessés dont un grave) entre des migrants kurdes et afghans a détruit à $80 \%$ le camp et ses "shelters " (abris)'. Cet incendie sert désormais à l'État comme preuve de l'inefficacité de la politique d'accueil du maire de GrandeSynthe. Immédiatement après l'incendie, le préfet du Nord a indiqué que le camp ne pourrait pas être reconstruit. Le ministre de l'Intérieur s'est rendu sur place avec le ministre du Logement et a déclaré : " II n'y aura plus de camp de La Linière, ni sous cette forme, ni sous une autre. " L'État reste donc ferme dans sa volonté d'éviter l'installation en France, et en particulier sur le littoral, de campements dits "sauvages " d'exilés. Quant au maire de Grande-Synthe, il a réaffirmé sa volonté de tendre la main aux migrants : "Ces actes criminels n'affectent en rien ma détermination de fraternité républicaine. Ce qui s'est passé ne remet rien en cause $^{2}$. " Le député Christian Hutin en campagne pour les législatives a rétorqué : "Cette générosité a été naïve. La Linière est devenue un magasin pour les passeurs?."
Si l'incendie à Grande-Synthe sert d'argument politique, il n'en demeure pas moins qu'il s'agit d'un phénomène fréquent à partir du moment où se construisent des squats, des «jungles » ou des camps, où se concentre une population démunie. Les incendies peuvent être reliés à une actualité qui bouleverse le quotidien : quelques jours après le démantèlement de la "new jungle " ̀̀ Calais en octobre dernier, les tentes et les cabanes de bric et de broc ont été incendiées, ce qui a accéléré le processus de destruction de la "new jungle». Plusieurs interprétations ont été avancées : pour la préfète de région, il s'agissait d'une tradition, précisant que des communautés ont pour coutume au pays de brûler leur maison avant de les quitter ; pour les associations, il s'agissait plutôt d'une expression de la colère des migrants; pour ces derniers, ils pointaient du doigt policiers et militants associatifs. Les incendies se déclenchent aussi suite à des accidents liés à des conditions de vie précaires : un feu qu'on brûle sous un hangar en tôle car il n'y a pas de chauffage, un dysfonctionnement au niveau d'une bouteille de gaz. Les incendies peuvent être également liés à des représailles - comme cela semble être le cas pour le camp de La Linière - suite à des bagarres interethniques et qui sont susceptibles d'être 
Le 20 avril 2017, plus d'une semaine après l'incendie du camp de Grande-Synthe, les engins de chantier terminaient de déblayer les derniers débris et chalets. II ne reste plus rien du camp. Photo Chloé Tisserand, 2017. @ CHLoÉ TISSERAND.

rattachées à un règlement de comptes entre passeurs.

Grande-Synthe est réputé pour être tenu par les passeurs kurdes, or plusieurs événements récents ont pu bouleverser l'organisation de cet espace reconfiguré, notamment avec l'arrivée récente d'un plus grand nombre de migrants afghans. Mais ce prisme ne peut résumer à lui seul l'état de tension d'un camp. Depuis la fermeture de la «new jungle » en octobre dernier à Calais, Grande-Synthe est le seul camp à proximité de l'Angleterre, les autres camps étant à l'intérieur des terres ou plus éloignés sur le littoral. L'augmentation du nombre d'exilés (la population a doublé depuis octobre dernier), parce que Grande-Synthe représente un sas avant de tenter le passage à Calais, l'engorgement des centres d'accueil et d'orientation (CAO) (certains migrants ont attendu quatre mois avant de pouvoir les intégrer), la guerre de territoires entre communautés, les conditions de vie déplorables ont créé un climat de tensions au sein de La Linière. L'incendie est l'aboutissement d'une série de paramètres qui ont détérioré progressivement la situation.

\section{Les vases communicants à petite et à grande échelle}

Depuis l'incendie, les migrants sont bringuebalés d'un lieu à l'autre : du camp au gymnase, du gymnase à la route, de la route à Calais, de Calais à Grande-Synthe, de Grande-Synthe à Calais, de Grande-Synthe au CAO, un système de vases communicants finit par articuler les déplacements migratoires. Sur les 1500 migrants qui vivaient dans le camp de La Linière, près de 500 ont été abrités en urgence dans trois gymnases de la ville et 


\section{FRONTIĖRES}

par communautés, de manière à ce qu'Afghans et Kurdes soient séparés. Certains migrants ont perdu leurs effets personnels et leurs papiers dans l'incendie. Un appel à la solidarité a été lancé par les associations afin de collecter des vêtements, des produits d'hygiène, des couvertures, une aide de 15000 euros a été débloquée par le Secours populaire. Le maire de Grande-

Depuis l'incendie, les migrants sont bringuebalés d'un lieu à l'autre : du camp au gymnase, du gymnase

à la route, de la route à Calais, de Calais à GrandeSynthe, de Grande-Synthe à Calais, de Grande-Synthe au $\mathrm{CAO}$, un système de vases communicants finit par articuler les déplacements tion qui gérait le camp, l'Afeji, migratoires.

Synthe a aussi lancé un appel national afin d'aider les exilés sans abris qui erraient au bord des routes. 250 exilés kurdes ont essayé de former un camp à Puythouck où ils ont été délogés pour être placés dans des gymnases. Les salariés de l'associaétaient auprès des exilés dans ces hébergements d'urgence. Ils sont cinquante-deux à s'interroger sur leur avenir, l'État semble dire qu'ils ne seront pas au chômage technique et qu'ils n'ont pas de crainte à avoir pour leur emploi ${ }^{4}$

Des départs de migrants placés dans les gymnases du Dunkerquois vers les CAO ont été organisés, d'abord dans l'Aisne, à Douai, à Aniche, puis partout en France (1061 personnes ont été relogées selon les organisateurs). Certains exilés en partance pour les CAO ont indiqué qu'ils reviendraient sur le littoral afin de passer en Angleterre. On assiste, notamment à Calais, à un retour des migrants qui ont été placés dans ces structures d'accueil ouvertes par le gouvernement en octobre dernier pour désengorger Calais. Si certains exilés, pour qui le dispositif est un levier, ont choisi d'aller en CAO pour effectuer une demande d'asile en France, d'autres ont fait ce choix dans la précipitation et par peur de l'expulsion s'ils restaient. Cela leur a également permis d'obtenir un abri le temps que la situation à Calais se calme (présence de CRS, multiplication des contrôles, politique anti-squats). Le retour des migrants à Calais témoigne aussi d'une certaine façon de l'échec de cet acharnement qu'ont les autorités à vouloir contrôler les exilés en dépit de leur choix migratoire et à les orienter vers un parcours migratoire préformaté. Elles semblent refuser la part de latitude que comporte la migration. Vouloir l'empêcher, "c'est comme empêcher le jour de succéder à la nuit ${ }^{5}$ ». II semblerait d'ailleurs que l'État n'ait pas pu prendre en charge tous les migrants de la Linière : environ 400 auraient pris la route vers Calais, dont 200 qui étaient hébergés dans un gymnase réquisitionné à Craywick, commune située près de Grande-Synthe. 